\title{
PENGARUH PENGUASAAN TEKNOLOGI DAN DISIPLIN KERJA TERHADAP KINERJA GURU DENGAN PRODUKTIVITAS SEBAGAI VARIABEL INTERVENING PADA SEKOLAH XXX
}

\author{
Yani, Amri Darwis, Yulina Eva Riany \\ Universitas Terbuka (UT) Jakarta, Indonesia \\ Email: yaniyenyen@gmail.com, amridarwis47@gmail.com, yriany@apps.ipb.ac.id
}

\begin{abstract}
The performance of human resources owned by the organization is a useful asset for the organization to achieve the goal. Quality and high-performance human resources are the expectations of every organization or company to improve the performance of its company. High human resource performance can benefit organizations with greaterprofitability. The purpose of this study is (1.) Analyzing the influence of technological control on productivity in xxx schools. (2.) analyze the influence of work discipline on productivity in xxx schools. (3.) analyze the influence of technological mastery on employee performance in $x x x$ schools. (4.) analyze the effect of work discipline on employee performance in xxx school. (5.) analyze the effect of productivity on employee performance in xxx schools. The research method used is descriptive quantitative method. Descriptive methods are used to learn aspects of who, what, when and how of suatu topic. A simple descriptive concerns a univariate question or hypothesis regarding, or expresses something about, the magnitude, shape, distribution, or existence of a variable. The results showed that there is a significant and positive influence of technological mastery on employee performance. The coefficient of determination is 0.653 which means that the amount of technological mastery influence on employee performance is $65.3 \%$ and the remaining $34.7 \%$ is another factor that is not studied. There is an influence of technological mastery on productivity in xxx schools. This result explains that teachers who can master and use technology-based work equipment well will have good productivity.
\end{abstract}

Keywords: technology master; discipline; productivity; employee performance

\section{Abstrak}

Kinerja sumber daya manusia yang dimiliki organisasi merupakan aset yang berguna bagi organisasi untuk mencapai tujuan. Sumber daya manusia yang berkualitas dan berkinerja tinggi menjadi harapan setiap organisasi atau perusahaan untuk meningkatkan kinerja perusahaannya. Kinerja sumber daya manusia yang tinggi dapat menguntungkan organisasi dengan perolehan keuntungan yang lebih besar. Tujuan penelitian ini adalah Pertama, Menganalisis pengaruh penguasan teknologi terhadap produktivitas di sekolah xxx. Kedua, menganalisis pengaruh disiplin kerja terhadap produktivitas di sekolah xxx. Ketiga, menganalisis pengaruh penguasaan teknologi terhadap kinerja karyawan di sekolah xxx. Keempat,

\begin{tabular}{ll}
\hline How to cite: & Yani, Amri Darwis dan Yulina Eva Riany (2021) Pengaruh Penguasaan Teknologi dan Disiplin \\
& Kerja terhadap Kinerja Guru dengan Produktivitas Sebagai Variabel Intervening pada Sekolah XXX, \\
& 3(6). https://doi.org/10.36418/syntax-idea.v3i6.1233 \\
E-ISSN: & 2684-883X \\
Published by: & Ridwan Institute
\end{tabular}


menganalisis pengaruh disiplin kerja terhadap kinerja karyawan di sekolah xxx. Kelima, menganalisis pengaruh produktivitas terhadap kinerja karyawan di sekolah xxx. Metode penelitian yang digunakan adalah metode deskriptif kuantitatif. Metode deskriptif digunakan untuk mempelajari aspek siapa, apa, bilamana dan bagaimana dari suatu topik. Deskriptif sederhana menyangkut suatu pertanyaan atau hipotesis univariat mengenai, atau menyatakan sesuatu mengenai, besar, bentuk, distribusi, atau keberadaan suatu variabel. Hasil penelitian menunjukkan bahwa terdapat pengaruh signifikan dan positif penguasaan teknologi terhadap kinerja karyawan. Koefisien determinasinya adalah 0,653 yang berarti besarnya pengaruh penguasaan teknologi terhadap kinerja karyawan adalah sebesar 65,3\% dan sisanya sebesar $34,7 \%$ adalah faktor lain yang tidak diteliti.Terdapat pengaruh penguasaan teknologi terhadap produktivitas di sekolah xxx. Hasil ini menjelaskan bahwa guru yang dapat mengusai dan menggunakan peralatan kerja berbasis teknologi dengan baik maka akan memiliki produktivitas yang juga baik.

Kata Kunci: penguasaan teknologi; disiplin kerja; produktivitas; kinerja karyawan

\section{Pendahuluan}

Kinerja sumber daya manusia yang dimiliki organisasi merupakan aset yang berguna bagi organisasi untuk mencapai tujuan. Sumber daya manusia yang berkualitas dan berkinerja tinggi menjadi harapan setiap organisasi atau perusahaan untuk meningkatkan kinerja perusahaannya. Kinerja sumber daya manusia yang tinggi dapat menguntungkan organisasi dengan perolehan keuntungan yang lebih besar.

Kinerja adalah nilai serangkaian perilaku pekerja yang memberikan kontribusi, baik secara positif maupun negatif untuk mencapai tujuan organisasi (Colquitt, J. A., Jweffery A. L, 2011). Tercapainya tujuan suatu organisasi atau lembaga pendidikan hanya dimungkinkan karena upaya para pelaku yang terdapat pada organisasi atau lembaga pendidikan tersebut. Dalam hal ini sebenarnya terdapat hubungan yang erat antara kinerja perorangan dengan kinerja lembaga pendidikan atau kinerja organisasi. Dengan kata lain bila kinerja karyawan tinggi, maka kemungkinan besar kinerja perusahaan juga tinggi.

Guru yang bekerja di sekolah xxx tempat penelitan ini diselenggarakan harus ditingkatkan kinerjanya agar dapat bersaing dengan sekolah lain. Sekolah yang bermutu dan baik mencerminkan kinerja guru. Sekolah yang bermutu dan baik akan menarik banyak jumlah siswa, begitu pun sebaliknya.

Hal ini dapat dilihat dari laporan penelitian yang dilakukan oleh (Kholidia Masitah, 2017) yang mengungkapkan bahwa jumlah peserta didik di SMP Muhammadiyah 1 Surabaya terus mengalami peningkatan. Pada tahun ajaran 2013/2014 terdapat 12 rombel (rombongan belajar, tahun ajaran 2014/2015 sebanyak 13 rombel, tahun ajaran 2015/2016 dan 2016/2017 sebanyak 14 rombel, dan pada tahun ajaran 2016/2017. Dalam penelitian ini dijelaskan juga bahwa peningkatan jumlah siswa tidak terlepas dari strategi manajemen yang berusaha memberikan kesan yang baik SMP Muhammadiyah 1 Surabaya kepada masyarakat. Tenaga pendidik di sekolah ini selalu melaksanakan tugas pokok sesuai fungsinya dengan baik dan bertanggung jawab. Di 
sekolah ini pembelajaran telah disampaikan dengan berbasis IT yang didukung oleh komputerisasi dan LCD.

Apa yang terjadi di SMP Muhammadiyah 1 Surabaya tidak terjadi di sekolah xxx tempat peneliti menyelenggarakan penelitian. Sebaliknya, jumlah siswa di sekolah ini terus mengalami penurunan. Hal ini menunjukan kinerja guru masih masih belum optimal. Kurang optimalnya kinerja guru atau karyawan dapat dilihat dari jumlah siswa dari tahun 2015-2019 tidak bertambah secara signifikan. Data jumlah siswa dapat disajikan pada Tabel 1.

Tabel 1

Data Jumlah Siswa xxx 2015-2019

\begin{tabular}{lccccc}
\hline \multicolumn{1}{c}{ Unit } & $\mathbf{2 0 1 5}$ & $\mathbf{2 0 1 6}$ & $\mathbf{2 0 1 7}$ & $\mathbf{2 0 1 8}$ & $\mathbf{2 0 1 9}$ \\
\hline TK & 261 & 276 & 295 & 284 & 277 \\
\hline SD & 462 & 470 & 482 & 491 & 523 \\
\hline SMP & 187 & 201 & 196 & 192 & 189 \\
\hline SMA & 164 & 160 & 183 & 156 & 142 \\
\hline SMK & 92 & 85 & 83 & 74 & 82 \\
\hline Jumlah & $\mathbf{1 0 7 4}$ & $\mathbf{1 1 0 7}$ & $\mathbf{1 1 5 6}$ & $\mathbf{1 1 9 7}$ & $\mathbf{1 2 1 3}$ \\
\hline
\end{tabular}

Sumber: Sekolah xxx, 2019

Berdasarkan Tabel 1 dapat dilihat bahwa jumlah siswa dari tahun 2015-2019 mengalami penurunan terutama untuk unit SMP/SMA/SMK dan secara keseluruhan tidak ada penambahan jumlah murid yang signifikan, hal ini menunjukkan bahwa kinerja guru di sekolah xxx masih kurang optimal. Unit TK dan SD dari tahun 20152019 jumlah siswa bertambah cukup signifikan, untuk TK bertambah 16 siswa sedangkan SD bertambah 61 siswa.

Berdasarkan data tersebut, peneliti kemudian melakukan survey pendahuluan terhadap 30 guru di sekolah xxx mengenai kinerja guru, produktivitas, penguasaan teknologi, dan disiplin kerja. Hasil penelitian dapat dilihat pada Table 2, 3, 4 dan 5.

Tabel 2

Survey Pendahuluan Kinerja Karyawan

\begin{tabular}{|c|c|c|c|c|}
\hline \multirow{2}{*}{ No } & \multirow{2}{*}{ Item pertanyaan } & \multicolumn{2}{|c|}{ Jawaban } & \multirow{2}{*}{ Jumlah } \\
\hline & & Ya & Tidak & \\
\hline 1 & $\begin{array}{l}\text { Dapat menyelesaikan tugas pekerjaan } \\
\text { tepat waktu }\end{array}$ & $\begin{array}{c}18 \\
(60 \%)\end{array}$ & $\begin{array}{c}12 \\
(40 \%)\end{array}$ & $\begin{array}{c}30 \\
(100 \%)\end{array}$ \\
\hline 2 & $\begin{array}{l}\text { Memiliki keterampilan yang tinggi dalam } \\
\text { melaksanakan tugas pekerjaan }\end{array}$ & $\begin{array}{c}19 \\
(63 \%)\end{array}$ & $\begin{array}{c}11 \\
(37 \%)\end{array}$ & $\begin{array}{c}30 \\
(100 \%)\end{array}$ \\
\hline 3 & $\begin{array}{l}\text { Dapat menyelesaikan pekerjaan sesuai } \\
\text { dengan standar sekolah }\end{array}$ & $\begin{array}{c}17 \\
(57 \%)\end{array}$ & $\begin{array}{c}13 \\
(43 \%)\end{array}$ & $\begin{array}{c}30 \\
(100 \%)\end{array}$ \\
\hline 4 & $\begin{array}{l}\text { Taat mengikuti prosedur yang diberikan } \\
\text { oleh pihak Sekolah }\end{array}$ & $\begin{array}{c}18 \\
(60 \%)\end{array}$ & $\begin{array}{c}12 \\
(40 \%)\end{array}$ & $\begin{array}{c}30 \\
(100 \%)\end{array}$ \\
\hline 5 & $\begin{array}{l}\text { Dapat melakukan pekerjaan dengan } \\
\text { seksama }\end{array}$ & $\begin{array}{c}19 \\
(63 \%)\end{array}$ & $\begin{array}{c}11 \\
(37 \%)\end{array}$ & $\begin{array}{c}30 \\
(100 \%)\end{array}$ \\
\hline 6 & $\begin{array}{l}\text { Dapat menyelesaikan sejumlah pekerjaan } \\
\text { sesuai dengan target }\end{array}$ & $\begin{array}{c}16 \\
(53 \%)\end{array}$ & $\begin{array}{c}14 \\
(47 \%)\end{array}$ & $\begin{array}{c}30 \\
(100 \%)\end{array}$ \\
\hline
\end{tabular}

Sumber: Survey Pendahuluan, diolah (2019) 
Tabel 3

Survey Pendahuluan Produktivitas

\begin{tabular}{|c|c|c|c|c|}
\hline \multirow{2}{*}{ No } & \multirow{2}{*}{ Item pertanyaan } & \multicolumn{2}{|c|}{ Jawaban } & \multirow{2}{*}{ Jumlah } \\
\hline & & Ya & Tidak & \\
\hline 1 & Memiliki kemampuan kerja di sekolah & $\begin{array}{c}18 \\
(58 \%)\end{array}$ & $\begin{array}{c}12 \\
(42 \%)\end{array}$ & $\begin{array}{c}30 \\
(100 \%)\end{array}$ \\
\hline 2 & $\begin{array}{l}\text { Memiliki peningkatan kerja yang sesuai } \\
\text { dengan kebutuhan di sekolah }\end{array}$ & $\begin{array}{c}17 \\
(57 \%)\end{array}$ & $\begin{array}{c}13 \\
(43 \%)\end{array}$ & $\begin{array}{c}30 \\
(100 \%)\end{array}$ \\
\hline 3 & $\begin{array}{l}\text { Dapat bekerja keras untuk kepentingan karir } \\
\text { di Sekolah }\end{array}$ & $\begin{array}{c}19 \\
(63 \%)\end{array}$ & $\begin{array}{c}11 \\
(37 \%)\end{array}$ & $\begin{array}{c}30 \\
(100 \%)\end{array}$ \\
\hline 4 & $\begin{array}{l}\text { Dapat menyelesaikan pekerjaan yang } \\
\text { menantang di Sekolah }\end{array}$ & $\begin{array}{c}16 \\
(53 \%)\end{array}$ & $\begin{array}{c}14 \\
(47 \%)\end{array}$ & $\begin{array}{c}30 \\
(100 \%)\end{array}$ \\
\hline 5 & $\begin{array}{l}\text { Memiliki tanggung jawab terhadap } \\
\text { pekerjaan di sekolah }\end{array}$ & $\begin{array}{c}20 \\
(67 \%)\end{array}$ & $\begin{array}{c}10 \\
(33 \%)\end{array}$ & $\begin{array}{c}30 \\
(100 \%)\end{array}$ \\
\hline 6 & $\begin{array}{l}\text { Dapat bekerja sama dengan rekan kerja di } \\
\text { sekolah }\end{array}$ & $\begin{array}{c}17 \\
(57 \%)\end{array}$ & $\begin{array}{c}13 \\
(43 \%)\end{array}$ & $\begin{array}{c}30 \\
(100 \%)\end{array}$ \\
\hline
\end{tabular}

Sumber: Survey Pendahuluan, diolah (2019)

Tabel 4

Survey Pendahuluan Penguasaan Teknologi

\begin{tabular}{|c|c|c|c|c|}
\hline \multirow{2}{*}{ No } & \multirow{2}{*}{ Item pertanyaan } & \multicolumn{2}{|c|}{ Jawaban } & \multirow{2}{*}{ Jumlah } \\
\hline & & Ya & Tidak & \\
\hline 1 & $\begin{array}{l}\text { Dapat mempermudah dalam proses kegiatan } \\
\text { belajar mengajar pada sekolah }\end{array}$ & $\begin{array}{c}18 \\
(60 \%)\end{array}$ & $\begin{array}{c}12 \\
(40 \%)\end{array}$ & $\begin{array}{c}30 \\
(100 \%)\end{array}$ \\
\hline 2 & $\begin{array}{l}\text { Dapat membantu menyelesaikan tugas } \\
\text { pekerjaan }\end{array}$ & $\begin{array}{c}16 \\
(53 \%)\end{array}$ & $\begin{array}{c}14 \\
(47 \%)\end{array}$ & $\begin{array}{c}30 \\
(100 \%)\end{array}$ \\
\hline 3 & $\begin{array}{l}\text { Dapat meningkatkan kemampuan yang lebih } \\
\text { baik dalam kegiatan belajar mengajar di } \\
\text { sekolah }\end{array}$ & $\begin{array}{c}18 \\
(60 \%)\end{array}$ & $\begin{array}{c}12 \\
(40 \%)\end{array}$ & $\begin{array}{c}30 \\
(100 \%)\end{array}$ \\
\hline 4 & $\begin{array}{l}\text { Dapat mempertinggi motivasi dalam } \\
\text { kegiatan belajar mengajar di Sekolah }\end{array}$ & $\begin{array}{c}20 \\
(67 \%)\end{array}$ & $\begin{array}{c}10 \\
(33 \%)\end{array}$ & $\begin{array}{c}30 \\
(100 \%)\end{array}$ \\
\hline 5 & $\begin{array}{l}\text { Dapat mempertinggi hasrat untuk bekerja di } \\
\text { Sekolah }\end{array}$ & $\begin{array}{c}20 \\
(67 \%)\end{array}$ & $\begin{array}{c}10 \\
(33 \%)\end{array}$ & $\begin{array}{c}30 \\
(100 \%)\end{array}$ \\
\hline 6 & $\begin{array}{l}\text { Dapat meningkatkan komitmen kerja dalam } \\
\text { kegiatan belajar mengajar di Sekolah }\end{array}$ & $\begin{array}{c}17 \\
(57 \%)\end{array}$ & $\begin{array}{c}13 \\
(43 \%)\end{array}$ & $\begin{array}{c}30 \\
(100 \%)\end{array}$ \\
\hline
\end{tabular}

Sumber: Survey Pendahuluan, diolah (2019)

Tabel 5

Survey Pendahuluan Disiplin Kerja

\begin{tabular}{|c|c|c|c|c|}
\hline \multirow{2}{*}{ No } & \multirow{2}{*}{ Item pertanyaan } & \multicolumn{2}{|c|}{ Jawaban } & \multirow{2}{*}{ Jumlah } \\
\hline & & Ya & Tidak & \\
\hline 1 & $\begin{array}{l}\text { Pekerjaan yang dibebankan harus sesuai } \\
\text { dengan kemampuan guru atau karyawan. }\end{array}$ & $\begin{array}{c}20 \\
(67 \%)\end{array}$ & $\begin{array}{c}10 \\
(33 \%)\end{array}$ & $\begin{array}{c}30 \\
(100 \%)\end{array}$ \\
\hline 2 & $\begin{array}{l}\text { Kepala Sekolah harus menjadi panutan guru } \\
\text { atau karyawan }\end{array}$ & $\begin{array}{c}18 \\
(60 \%)\end{array}$ & $\begin{array}{c}12 \\
(40 \%)\end{array}$ & $\begin{array}{c}30 \\
(100 \%)\end{array}$ \\
\hline 3 & $\begin{array}{l}\text { Guru atau karyawan memperoleh pelatihan, } \\
\text { bimbingan, arahan dan pengawasan dari } \\
\text { Kepala Sekolah. }\end{array}$ & $\begin{array}{c}17 \\
(57 \%)\end{array}$ & $\begin{array}{c}13 \\
(43 \%)\end{array}$ & $\begin{array}{c}30 \\
(100 \%)\end{array}$ \\
\hline 4 & $\begin{array}{l}\text { Guru atau karyawan memperoleh sanksi yang } \\
\text { keras jika melanggar peraturan }\end{array}$ & $\begin{array}{c}20 \\
(67 \%)\end{array}$ & $\begin{array}{c}10 \\
(33 \%)\end{array}$ & $\begin{array}{c}30 \\
(100 \%)\end{array}$ \\
\hline 5 & $\begin{array}{l}\text { Dapat menciptakan hubungan harmonis antar } \\
\text { semua guru atau karyawan }\end{array}$ & $\begin{array}{c}16 \\
(53 \%)\end{array}$ & $\begin{array}{c}14 \\
(47 \%)\end{array}$ & $\begin{array}{c}30 \\
(100 \%)\end{array}$ \\
\hline
\end{tabular}




\begin{tabular}{|c|c|c|c|c|}
\hline \multirow{2}{*}{ No } & \multirow{2}{*}{ Item pertanyaan } & \multicolumn{2}{|c|}{ Jawaban } & \multirow{2}{*}{ Jumlah } \\
\hline & & Ya & Tidak & \\
\hline 6 & $\begin{array}{l}\text { Kepala Sekolah harus bersikap berani dan } \\
\text { tegas kepada guru atau karyawan }\end{array}$ & $\begin{array}{c}19 \\
(63 \%)\end{array}$ & $\begin{array}{c}11 \\
(37 \%)\end{array}$ & $\begin{array}{c}30 \\
(100 \%)\end{array}$ \\
\hline
\end{tabular}

Sumber: Survey Pendahuluan, diolah (2019)

Hasil survey pendahuluan pada Tabel 3 menunjukan kemampuan kerja, kerja sama antar rekan masih kurang maksimal. Manajemen perusahaan harus berusaha untuk lebih meningkatkan kemampuan kerja, tingkat kerjasama dan lain-lain agar kinerja karyawan meningkat sehingga kinerja perusahaan juga mengalami peningkatan. Produktivitas kerja yang dimiliki guru seperti kemampuan kerja, tanggung jawab, bekerja sama dan lain-lain menjadikan karyawan memiliki terampil dalam bekerja, lebih semangat, mencapai tujuan secara bersama, lebih mudah memahami pekerjaan sehingga hal ini dapat mempengaruhi kinerja karyawan menjadi meningkat. Hal ini sesuai dengan penelitian yang dilakukan oleh (Bahri, 2016) yang menyatakan bahwa produktivas kerja berpengaruh terhadap kinerja karyawan.

Penguasaan teknologi oleh guru di sekolah xxx masih kurang maksimal, sesuai hasil survey pendahuluan pada Tabel 4 Manajemen perusahaan harus berusaha untuk lebih meningkatkan penguasaan teknologi yang lebih baik kepada guru agar produktivitas dan kinerja guru meningkat sehingga kinerja sekolah xxx juga mengalami peningkatan. Peneliti melakukan observasi pada laporan hasil penelitian yang dilakukan oleh peneliti terdahulu untuk meningkatkan produktivitas dan kinerja guru. (Karim, 2016) dalam penelitiannya melaporkan bahwa penguasaan teknologi informasi, pendidikan dan disiplin kerja secara simultan berpengaruh signifikan terhadap produktivitas kerja. Teknologi informasi mempunyai pengaruh positif dan signifikan terhadap produktivitas karyawan bank, (Mutuku \& Nyaribo, 2015).

Berdasarkan hasil survey pendahuluan disiplin kerja pada Tabel 5, terlihat bahwa disiplin kerja yang dimiliki guru masih kurang maksimal. Untuk itu manajemen sekolah harus dapat memberikan dorongan dan rangsangan kepada guru agar memiliki disiplin yang tinggi. Dengan disiplin kerja yang tinggi maka guru dapat bekerja dengan penuh semangat dan dapat menyelesaikan pekerjaan sesuai target, sehingga kinerja guru akan mengalami peningkatan. Hal ini sesuai dengan beberapa laporan penelitian terdahulu. (Suyono, 2014) melaporkan bahwa disiplin mempunyai pengaruh positif dan signifikan terhadap kinerja karyawan. Disiplin kerja mempunyai pengaruh signifikan terhadap kinerja karyawan, (Noel, Lapian, \& Pandowo, 2017) dan (Jeffrey \& Soleman, 2017).

Dalam mengatasi permasalahan yang ada di unit SMP, SMA dan SMK serta menjaga agar tidak terjadi pada unit TK dan SD maka perlu dilakukan upaya dengan jalan meningkatkan kinerja guru. Peningkatan kinerja guru ini diharapkan agar untuk tahun berikutnya dapat menambah jumlah siswa secara signifikan mulai dari unit TK, SD, SMP, SMA dan SMK.

Banyak faktor yang dapat mempengaruhi peningkatan kinerja guru salah satunya adalah produktivitas. Laporan penelitian yang dilakukan oleh (Bahri, 2016) menyatakan bahwa produktivitas berpengaruh positif dan signifikan terhadap kinerja pegawai. 
Dalam penelitian yang dilakukan oleh (Bahri, 2016) variabel-variabel yang memengaruhi produktivitas adalah pengembangan karir dan kompetensi kerja. (Sridaryono, 2019) melaporkan bahwa produktivitas kerja secara langsung berpengaruh positif dan signifikan terhadap kinerja. Variabel yang mempengaruhi produktivitas dalam penelitian ini adalah kompetensi dan kompensasi.

Penelitian ini bertujuan untuk mengetahui faktor-faktor yang memengaruhi kinerja guru di sekolah xxx sehingga manajemen dapat meningkatkan kinerja guru serta mempertahankan bahkan menarik jumlah siswa lebih banyak. Setelah membaca laporan penelitian terdahulu dan mempertimbangkan keterbatasan yang dimiliki peneliti, maka penelitian ini hanya meneliti penguasaan teknologi, disiplin kerja dan produktivitas yang diduga mempunyai pengaruh terhadap kinerja guru di sekolah xxx.

\section{Metode penelitian}

Penelitian ini dilaksanakan di sekolah xxx yang terletak di daerah Jakarta Barat dengan jumlah populasi sebanyak 119 guru dan menggunakan metode penelitian kuantitatif dengan pendekatan kausal. Jumlah sampel ini melebihi jumlah sampel yang disarankan oleh Krejcie dan Morgan tahun 1970, dimana ukuran sampel untuk populasi sebesar 120 orang adalah 92 responden. Data penelitian ini terdiri dari data primer dan data sekunder. Data primer diperoleh dari sekolah dan data sekunder diperoleh dari kuesioner. Kuesioner diberikan kepada 119 guru melalui aplikasi Google form. Data yang diperoleh dari kuesioner kemudian diolah menggunakan program SEM PLS.

\section{Hasil dan pembahasan}

\section{A. Karakteristik responden}

Karakteristik 119 guru yang merupakan sampel dalam penelitian ini terlihat pada Tabel 6 .

Tabel 6

Karakteristik Responden

\begin{tabular}{llcc}
\hline \multirow{2}{*}{ Karakteristik } & \multicolumn{1}{c}{ Kategori } & Frekuensi & Persentase \\
\hline \multirow{2}{*}{ Status } & Menikah & 58 & $48,7 \%$ \\
& Belum menikah & 61 & $51,3 \%$ \\
\cline { 2 - 4 } & Jumlah & 119 & 100 \\
\hline Jenis Kelamin & Laki-laki & 29 & $24,4 \%$ \\
& Perempuan & 90 & $75,6 \%$ \\
\cline { 2 - 4 } & Jumlah & 119 & 100 \\
\hline Usia & $<20$ tahun & 2 & $1,7 \%$ \\
& $>20-30$ tahun & 44 & $37 \%$ \\
& $>30-40$ tahun & 54 & $45,4 \%$ \\
& $>40-50$ tahun & 12 & $10,1 \%$ \\
& Di atas 50 tahun & 7 & $5,9 \%$ \\
\cline { 2 - 4 } & Jumlah & 119 & 100 \\
\hline Masa Kerja & $<5$ tahun & 60 & $50,4 \%$ \\
& $>5-10$ tahun & 44 & $37 \%$ \\
& $>10-15$ tahun & 15 & $12,6 \%$ \\
\hline
\end{tabular}




\begin{tabular}{llcc}
\hline \multirow{2}{*}{ Karakteristik } & \multicolumn{1}{c}{ Kategori } & Frekuensi & Persentase \\
\hline & Di atas 15 tahun & 0 & $0 \%$ \\
\cline { 2 - 4 } & Jumlah & 119 & 100 \\
\hline Pendidikan & Diploma & 4 & $3,4 \%$ \\
& S1 & 112 & $94,1 \%$ \\
& S2 & 3 & $2,5 \%$ \\
& S3 & 0 & $0 \%$ \\
\cline { 2 - 4 } & Jumlah & 119 & 100 \\
\hline
\end{tabular}

Sumber: Olahan Peneliti 2020

Responden berdasarkan status sesuai data pada Tabel 6 yang paling dominan adalah berstatus belum menikah sebesar 51, 3\% diikuti dengan responden berstatus menikah sebesar $48,7 \%$. Mayoritas responden berusia antara lebih dari 30 tahun sampai dengan 40 tahun, yaitu sebanyak 54 responden. Jumlah responden terbanyak kedua berusia antara lebih dari 20 tahun sampai dengan 30 tahun, yaitu sebanyak 44 reponden. Sebanyak 60 guru berkerja selama kurang dari 5 tahun. Sebanyak 44 guru telah bekerja selama lebih dari lima tahun sampai sepuluh tahun. Mayoritas responden atau guru di sekolah xxx pendidikan terakhirnya adalah Strata 1. Hanya dua guru yang melanjutkan pendidikan sampai jenjang Strata 2. Sebanyak 112 reponden mempengaruhi hasil penelitian ini yang semuanya menyelesaikan pendidikan sampai jenjang Strata 1.

\section{a) Model Partial Least Square (PLS)}

Pengujian hipotesis yang dilakukan pada penelitian ini menggunakan teknik analisis Partial Least Square (PLS) dengan program smartPLS 3.0. Model pengukuran untuk uji validitas dan reabilitas, koefisien determinasi model dan koefisien jalur untuk model persamaan, dapat dilihat dari hasil penelitian pada Gambar 1 dan Gambar 2.

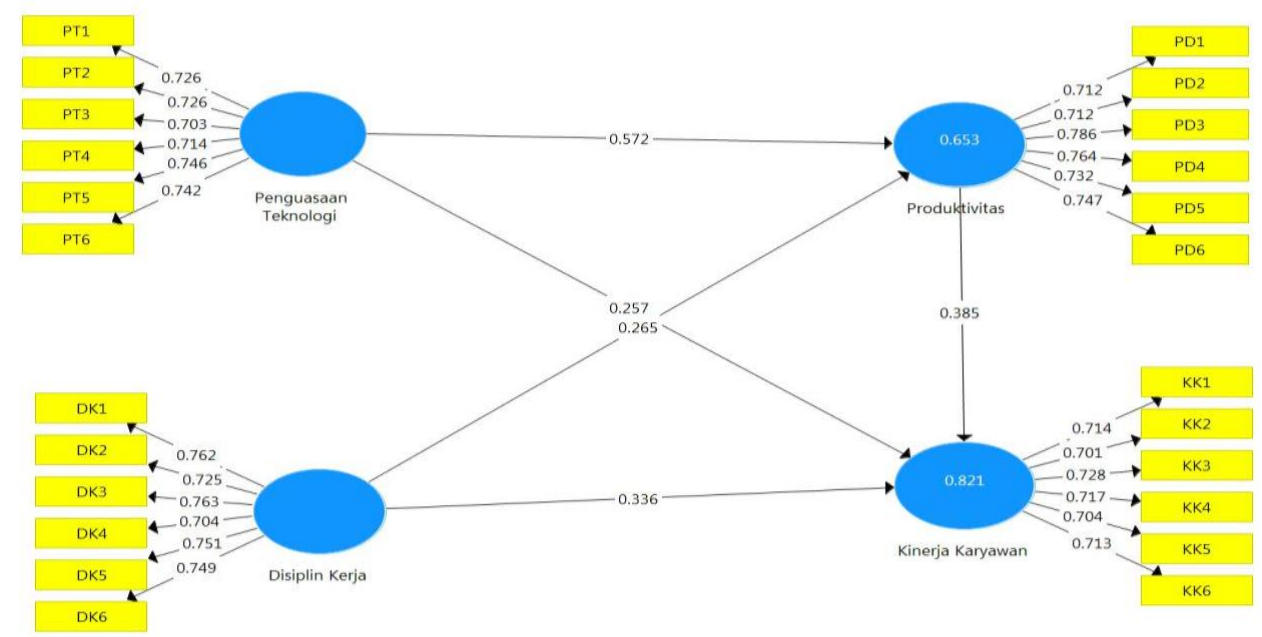

Gambar 1

Outer Model 


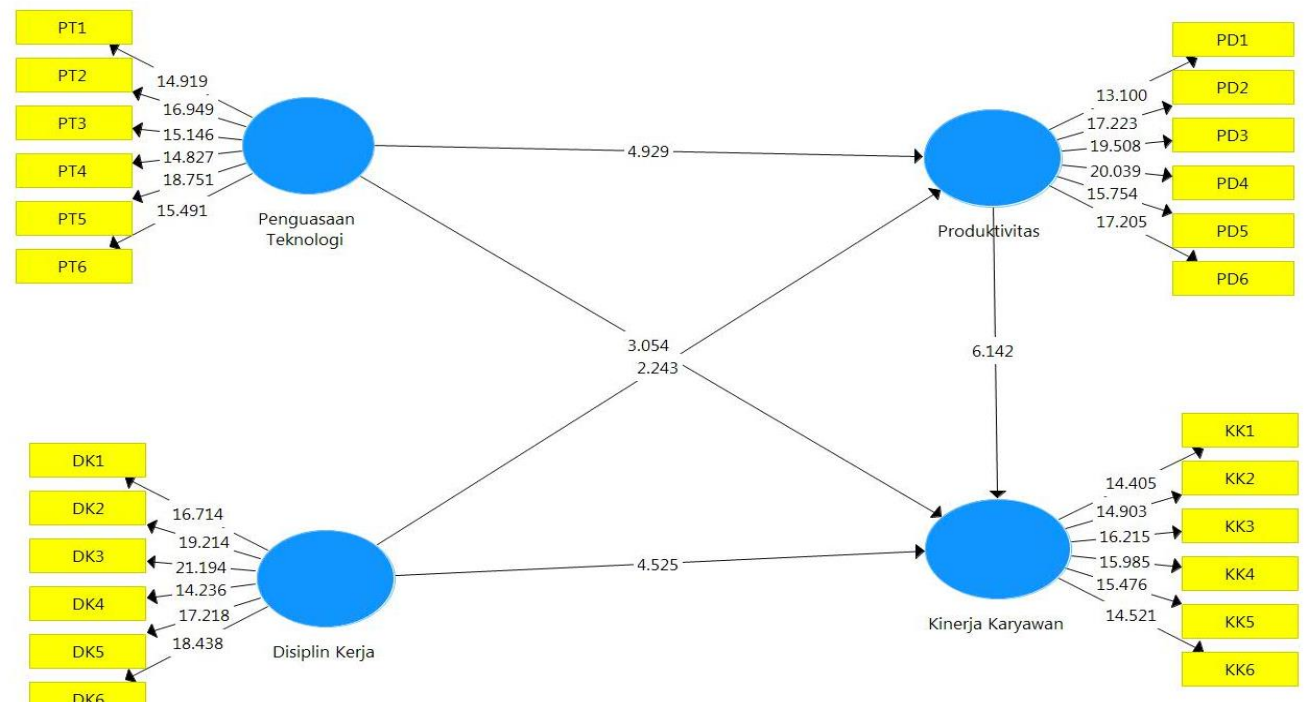

Gambar 2

Inner Model

\section{Evaluasi Outer Model}

\section{a. Convergent Validity}

Untuk menguji convergent validity digunakan nilai outer loading atau loading factor seperti yang terlihat pada gambar 1. Suatu indikator dinyatakan memenuhi convergent validity dalam kategori baik apabila nilai outer loading $>0,7$. Berikut adalah nilai outer loading dari masing-masing indikator pada variabel penelitian yang disajikan pada Tabel 7.

Tabel 7

Outer Loading

\begin{tabular}{lcc}
\hline \multirow{2}{*}{ Variabel } & Indikator & Outer Loading \\
\hline Penguasaan Teknologi (X1) & PT1 & 0,726 \\
\cline { 2 - 3 } (Williams, Sawyer, & PT2 & 0,726 \\
\cline { 2 - 3 } Hutchinson, 1999) & PT3 & 0,703 \\
\cline { 2 - 3 } & PT4 & 0,714 \\
\cline { 2 - 3 } & PT5 & 0,746 \\
\hline Disiplin Kerja (X2) & PT6 & 0,742 \\
\cline { 2 - 3 } (Sutrisno, 2013) & DK1 & 0,762 \\
\cline { 2 - 3 } & DK2 & 0,725 \\
\cline { 2 - 3 } & DK3 & 0,763 \\
\cline { 2 - 3 } & DK4 & 0,704 \\
\hline Produktivitas (Z) & DK56 & 0,751 \\
\cline { 2 - 3 } (Ferreira \& Du Plessis, 2009) & PD1 & 0,749 \\
\cline { 2 - 3 } & PD2 & 0,712 \\
\cline { 2 - 3 } & PD3 & 0,712 \\
\cline { 2 - 3 } & PD4 & 0,786 \\
\cline { 2 - 3 } & PD5 & 0,764 \\
\hline Kinerja Karyawan (Y) & PD6 & 0,747 \\
\cline { 2 - 3 } (Colquitt, J. A., Jweffery A. L, & KK2 & 0,714 \\
\cline { 2 - 3 } & &
\end{tabular}




\begin{tabular}{|c|c|c|}
\hline Variabel & Indikator & Outer Loading \\
\hline \multirow[t]{3}{*}{ 2011) } & KK4 & 0,717 \\
\hline & KK5 & 0,704 \\
\hline & KK6 & 0,713 \\
\hline
\end{tabular}

Sumber: Hasil Pengolahan PLS, 2020

Berdasarkan data pada Tabel 7 terlihat bahwa masing-masing indikator variabel penelitian secara keseluruhan memiliki nilai outer loading $>0,7$. Hal ini menunjukkan bahwa tidak ada indikator variabel yang nilai outer loading-nya di bawah 0,5, sehingga semua indikator dinyatakan layak atau valid untuk digunakan penelitian dan dapat digunakan untuk analisis lebih lanjut.

\section{b. Discriminant Validity}

Pada bagian ini akan diuraikan hasil uji discriminant validity. Uji discriminant validity dilakukan dengan melihat nilai average variant extracted (AVE) untuk masing-masing indikator dipersyaratkan nilainya harus $>0,5$ untuk model yang baik. Berikut disajikan hasil uji discriminant validity pada Tabel 8 .

\section{Tabel 8}

Average Variant Extracted (AVE)

\begin{tabular}{cc}
\hline Variabel & AVE \\
\hline Penguasaan Teknologi & 0,528 \\
\hline Disiplin Kerja & 0,552 \\
\hline Produktivitas Kerja & 0,551 \\
\hline Kinerja Karyawan & 0,508 \\
\hline Penguasaan Teknologi & 0,528 \\
\hline Sumber: Hasil Pengolahan PLS, 2020
\end{tabular}

Berdasarkan Tabel 8 terlihat bahwa nilai AVE untuk semua variabel penelitian memiliki nilai $>0,5$. Dengan demikian dapat dinyatakan bahwa setiap variabel penelitian telah memiliki discriminant validity yang baik.

\section{c. Composite Reliability}

Composite Reliability merupakan bagian yang digunakan untuk menguji nilai reliabilitas indikator-indikator pada suatu variabel. Suatu variabel dapat dinyatakan memenuhi composite reliability apabila memiliki nilai composite reliability > 0,6. Pada Tabel 9 disajikan nilai composite reliability dari masing-masing variabel penelitian. 
Tabel 9

Composite Reliablity

\begin{tabular}{lc}
\hline \multicolumn{1}{c}{ Variabel } & Composite Reliablity \\
\hline Penguasaan Teknologi & 0,870 \\
\hline Disiplin Kerja & 0,881 \\
\hline Produktivitas Kerja & 0,880 \\
\hline Kinerja Karyawan & 0,861 \\
\hline Penguasaan Teknologi & 0,870 \\
\hline \multicolumn{1}{c}{ Sumber: Hasil Pengolahan PLS, 2020}
\end{tabular}

Berdasarkan Tabel 9 terlihat bahwa nilai composite reliability semua variabel penelitian > 0,6. Hal ini menunjukkan bahwa masing-masing variabel telah memenuhi composite realibility sehingga dapat disimpulkan bahwa keseluruhan variabel memiliki tingkat realibilitas yang tinggi.

\section{d. Cronbach Alpha}

Uji realibilitas dengan composite reability di atas dapat diperkuat dengan menggunakan nilai cronbach alpha. Suatu variabel dapat dinyatakan reliabel atau memenuhi cronbach alpha apabila memiliki nilai cronbach alpha > 0,75. Tabel 10 menunjukkan nilai cronbach alpha dari masingmasing variabel.

Tabel 10

Cronbach Alpha

\begin{tabular}{lc}
\hline \multicolumn{1}{c}{ Variabel } & Cronbach Alpha \\
\hline Penguasaan Teknologi & 0,821 \\
\hline Disiplin Kerja & 0,837 \\
\hline Produktivitas Kerja & 0,837 \\
\hline Kinerja Karyawan & 0,807 \\
\hline Penguasaan Teknologi & 0,821 \\
\hline
\end{tabular}

Sumber: Hasil Pengolahan PLS, 2020

Berdasarkan Tabel 10 terlihat bahwa nilai cronbach alpha dari masing-masing variabel penelitian > 0,7. Dengan demikian hasil ini menunjukkan bahwa masing-masing variabel penelitian telah memenuhi persyaratan nilai cronbach alpha, sehingga dapat disimpulkan bahwa keseluruhan variabel memiliki tingkat reliabilitas yang tinggi.

\section{B. Hasil uji hipotesis}

\section{Pengaruh Langsung}

Pendekatan analisis structural Equation Model (SEM) dengan menggunakan Partial Least Square (PLS) digunakan untuk menguji hipotesis karena tidak memerlukan sampel besar. Populasi dalam penelitian ini berjumlah 119 yang semuanya dijadikan sampel. Kuesioner disebarkan menggunakan Google Formulir. Link dikirimkan melalui aplikasi whatsapp untuk diisi oleh 
guru mulai tanggal 24 Juni sampai 26 Juni 2020. Pengujian pertama dilakukan untuk mengetahui hubungan dari penguasaan teknologi, disiplin kerja dan produktivitas secara lansung terhadap variabel dependent kinerja karyawan. Berdasarkan olah data yang telah dilakukan, hasilnya dapat digunakan untuk menjawab hipotesis pada penelitian ini. Uji hipotesis pada penelitian ini dilakukan dengan melihat nilai T-Statistics dan nilai P-Values. Hipotesis penelitian dapat dinyatakan diterima apabila nilai $P$-Values $<0,05$. Hasil uji hipotesis pengaruh langsung yang diperoleh dalam penelitian ini melalui inner model disajikan pada Tabel 11.

Tabel 11

Pengaruh Langsung

\begin{tabular}{ccccc}
\hline $\begin{array}{c}\text { Hipotesi } \\
\text { s }\end{array}$ & Pengaruh & $\begin{array}{c}\text { T- } \\
\text { Statisti } \\
\mathbf{k}\end{array}$ & $\begin{array}{c}\text { P- } \\
\text { Value } \\
\mathbf{s}\end{array}$ & Hasil \\
\hline H1 & $\begin{array}{c}\text { Penguasaan Teknologi => } \\
\text { Produktivitas }\end{array}$ & 4,929 & 0,000 & Diterima \\
\hline H2 & Disiplin Kerja => Produktivitas & 2,243 & 0,025 & Diterima \\
\hline H3 & Penguasaan Teknologi => Kinerja \\
Guru & 3,054 & 0,002 & Diterima \\
\hline H4 & Disiplin Kerja => Kinerja Guru & 4,525 & 0000 & Diterima \\
\hline H5 & Produktivitas => Kinerja Guru & 6,142 & 0,000 & Diterima \\
\hline \multicolumn{4}{c}{ Sumber: Hasil Pengalahan PLS, 2020} \\
& & &
\end{tabular}

a. Pengaruh Tidak Langsung

Dilakukan pengujian pada $\mathrm{H} 6$ dan $\mathrm{H} 7$ untuk mengetahui pengaruh tidak langsung variabel independent terhadap variabel dependent melalui peran variabel mediator produktivitas. Pengaruh secara tidak langsung penguasaan teknologi terhadap kinerja karyawan melalui produktivitas dan pengaruh disiplin kerja terhadap kinerja karyawan melalui produktivitas dapat dilihat dari total indirect effect yang disajikan pada Tabel 12.

Tabel 12

Pengaruh Tidak Langsung

\begin{tabular}{ccccc}
\hline Hipotesis & Pengaruh & $\begin{array}{c}\text { T- } \\
\text { Statistik }\end{array}$ & $\begin{array}{c}\text { P- } \\
\text { Values }\end{array}$ & Hasil \\
\hline H6 & $\begin{array}{c}\text { Penguasaan Tekonolgi => Kinerja } \\
\text { Karyawan melalui Produktivitas }\end{array}$ & 3,443 & 0,001 & Diterima \\
\hline H7 & $\begin{array}{c}\text { Disiplin Kerja => Kinerja } \\
\text { Karyawan melalui Produktivitas }\end{array}$ & 2,166 & 0,031 & Diterima \\
\hline
\end{tabular}

Sumber: Hasil Pengalahan PLS, 202

\section{Pengaruh penguasaan teknologi terhadap produktivitas}

Berdasarkan hasil penelitian diperoleh nilai t-value 4,929 > 1,96 artinya ada pengaruh yang signifikan dan positif penguasaan teknologi terhadap produktivitas. Koefisien determinasinya adalah 0,653 yang berarti besarnya pengaruh penguasaan teknologi terhadap kinerja karyawan adalah sebesar 65,3\% dan sisanya sebesar 34,7\% adalah faktor lain yang tidak diteliti. 
Penguasaan teknologi merupakan seperangkat keterampilan dan pemahaman yang dibutuhkan oleh individu sehingga memungkinkan penggunaan teknologi informasi yang sesuai dengan kebutuhan mereka (Oliver \& Towers, 2000). Penguasaan teknologi informasi yang dimiliki oleh karyawan atau guru dapat membuat suatu pekerjaan lebih mudah dikerjakan. Karyawan dapat menyelesaikan pekerjaan dengan lebih cepat dan mudah dengan adanya peralatan komputer dan dukungan teknologi internet sehingga informasi yang disampaikan ke atasan lebih cepat dan akurat. Sebagai guru dapat melaksanakan kegiatan belajar mengajar dengan lebih mudah dan cepat dipahami oleh peserta didik karena menggunakan teknologi informasi seperti persentasi dengan komputer, animasi bergerak dan lain sebagainya. Penguasaan teknologi informasi ini dapat mempengaruhi produktivitas kerja guru atau karyawan.

Hasil penelitian in mendukung penelitian yang dilakukan oleh (Wardoyo, 2016), (Karim, 2016), (Mutuku \& Nyaribo, 2015) yang menyatakan bahwa penguasaan teknologi informasi berpengaruh terhadap produktivitas kerja karyawan.

\section{Pengaruh disiplin kerja terhadap produktivitas}

Berdasarkan hasil penelitian diperoleh nilai t-value 2,243>1,96 artinya ada pengaruh disiplin kerja terhadap produktivitas. Koefisien determinasinya adalah 0,653 yang berarti besarnya pengaruh disiplin kerja terhadap produktivitas adalah sebesar $65,3 \%$ dan sisanya sebesar $34,7 \%$ adalah faktor lain yang tidak diteliti.

Disiplin kerja disiplin merupakan suatu bentuk pelatihan yang menegakkan aturan organisasi (Mathis, 2011). Disiplin menunjukkan suatu kondisi atau sikap hormat yang ada pada diri karyawan terhadap peraturan dan ketetapan perusahaan. Dengan demikian bila peraturan atau ketetapan yang ada dalam perusahaan diabaikan, atau sering dilanggar, maka karyawan mempunyai disiplin yang buruk. Sebaliknya bila karyawan tunduk pada ketetapan perusahaan, menggambarkan adanya kondisi disiplin yang baik.

Disiplin kerja yang baik dapat dipengaruhi oleh beberapa faktor seperti besar kecilnya kompensasi, keteladanan kepemimpinan, aturan pasti dan keberanian pemimpin. Untuk itu perusahaan atau organisasi harus memperhatikan tingkat disiplin kerja karyawan agar tujuan organisasi dapat tercapai. Disiplin kerja yang tinggi dapat mempengaruhi produktivitas kerja karyawan.

Hasil penelitian ini mendukung penelitian yang dilakukan oleh (Wardoyo, 2016), (Zainal, 2017), (Saleh \& Utomo, 2018), (Karim, 2016) yang menyatakan bahwa disiplin kerja berpengaruh terhadap produktivitas karyawan.

\section{Pengaruh penguasaan teknologi terhadap kinerja karyawan}

Berdasarkan hasil penelitian diperoleh nilai t-value 3,054 > 1,96 artinya ada pengaruh positif dan signifikan penguasaan teknologi terhadap kinerja karyawan. Koefisien determinasinya adalah 0,821 yang berarti besarnya 
pengaruh penguasaan teknologi terhadap kinerja karyawan adalah sebesar 82,1\% dan sisanya sebesar $17,9 \%$ adalah faktor lain yang tidak diteliti.

Penguasaan teknologi informasi yang dimiliki oleh guru dapat membuat suatu pekerjaan lebih mudah dikerjakan. Guru dapat menyelesaikan pekerjaan dengan lebih cepat dan mudah dengan adanya peralatan komputer dan dukungan teknologi internet sehingga informasi yang disampaikan ke atasan lebih cepat dan akurat. Sebagai guru dapat melaksanakan kegiatan belajar mengajar dengan lebih mudah dan cepat dipahami oleh peserta didik karena menggunakan teknologi informasi seperti persentasi dengan komputer, animasi bergerak dan lain sebagainya. Penguasaan teknologi informasi ini dapat mempengaruhi kinerja guru atau karyawan.

Hasil penelitian ini mendukung penelitian yang dilakukan oleh (Saha, A., \& Majumder, 2017), (Oguche, 2017), (Yuvaraj \& Nadheya, 2018), (Nuskiya, 2018), (Muzakki, M. H., Susilo, H., \& Yuniarto, 2016) yang menyatakan babwa penguasaan teknologi informasi dapat berpengaruh terhadap kinerja guru atau karyawan.

\section{Pengaruh disiplin kerja terhadap kinerja karyawan}

Berdasarkan hasil penelitian diperoleh t-value 4,525 > 1,96 artinya ada pengaruh positif yang signifikan disiplin kerja terhadap kinerja karyawan. Koefisien determinasinya adalah 0,821 yang berarti besarnya pengaruh disiplin kerja terhadap kinerja karyawan adalah sebesar $82,1 \%$ dan sisanya sebesar $17,9 \%$ adalah faktor lain yang tidak diteliti.

Disipilin merupakan suatu bentuk pelatihan yang menegakkan aturan organisasi (Mathis, 2011). Dengan demikian bila peraturan atau ketetapan yang ada dalam perusahaan diabaikan, atau sering dilanggar, maka karyawan mempunyai disiplin yang buruk. Sebaliknya bila karyawan tunduk pada ketetapan perusahaan, menggambarkan adanya kondisi disiplin yang baik.

Disiplin kerja yang baik dapat berdampak pada pekerjaan lebih maksimal, lebih fokus, lebih cermat dan dapat mencapai target sesuai dengan standar yang ditetapkan. Sehingga hal ini dapat meningkatkan kinerja guru atau karyawan.

Hasil penelitian ini mendukung penelitian yang dilakukan oleh (Noel et al., 2017), (Suyono, 2014), (Jeffrey \& Soleman, 2017) yang menyatakan bahwa disiplin kerja berpengaruh terhadap kinerja karyawan.

\section{Pengaruh Produktivitas terhadap Kinerja Karyawan}

Berdasarkan hasil penelitian diperoleh nilai t-value 6,142>1,96 artinya ada pengaruh positif dan signifkan produktivitas terhadap kinerja karyawan. Koefisien determinasinya adalah 0,821 yang berarti besarnya pengaruh produktivitas terhadap kinerja karyawan adalah sebesar $82,1 \%$ dan sisanya sebesar $17,9 \%$ adalah faktor lain yang tidak diteliti.

Produktivitas adalah sikap karyawan terhadap pekerjaannya yang mencerminkan pengalaman-pengalaman menyenangkan maupun yang tidak menyenangkan dan berbagai harapan mengenai pengalaman-pengalaman di 
masa depan (Wexley \& Yukl, 1977). Produktivitas kerja yang dimiliki karyawan atau guru seperti kemampuan kerja, tanggung jawab, bekerja sama dan lain-lain menjadikan karyawan memiliki terampil dalam bekerja, lebih semangat, mencapai tujuan secara bersama, lebih mudah memahami pekerjaan sehingga hal ini dapat mempengaruhi kinerja karyawan menjadi meningkat. Hal ini sesuai dengan penelitian yang dilakukan oleh (Bahri, 2016), (Sridaryono, 2019) yang menyatakan bahwa produktivas kerja berpengaruh terhadap kinerja karyawan.

Hasil uji hipotesis pengaruh langsung yang diperoleh melalui inner model ditampilkan pada gambar 3.

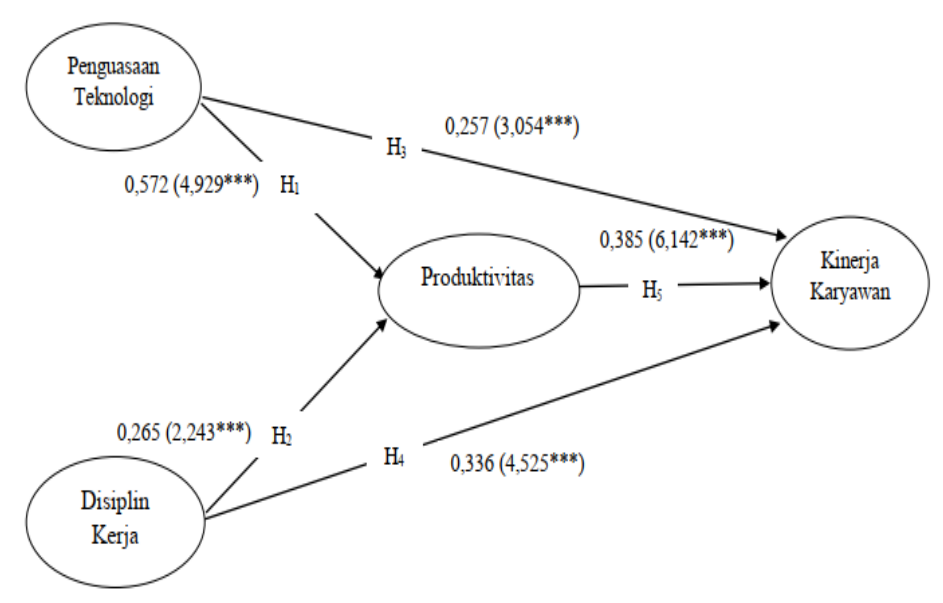

Gambar 3

Hasil Nilai t-value dan Koofisien Jalur pada Model Penelitian

\section{Pengaruh Penguasaan Teknologi terhadap Kinerja Karyawan melalui Produktivitas}

Berdasarkan hasil penelitian diperoleh nilai t-value 3,443>1,96 artinya produktivitas kerja dapat memediasi pengaruh antara penguasaan teknologi dengan kinerja karyawan. Penguasaan teknologi yang dimiliki oleh karyawan atau guru dapat memudahkan pekerjaannya, sehingga dapat memicu produktivitas kerja guru atau karyawan. Sehingga dengan adanya penguasaan teknologi ini akan meningkatkan produktivitas dan sekaligus dapat meningkatkan kinerja karyawan.

\section{Pengaruh Disiplin Kerja terhadap Kinerja Karyawan melalui Produktivitas}

Berdasarkan hasil penelitian diperoleh nilai t-value 2,166 > 1,96 artinya produktivitas kerja dapat memediasi pengaruh antara disiplin kerja dengan kinerja karyawan. Disiplin kerja tinggi yang dimiliki oleh guru atau karyawan dapat berdampak pada ketepatan jadwal penyelesaian pekerjaan atau sesuai dengan target yang telah ditetapkan, dapat bekerja lebih fokus. Sehingga dengan disiplin kerja yang tinggi dapat berpengaruh terhadap meningkatknya produktivitas kerja dan sekaligus dapat meningkatkan kinerja karyawan. 


\section{Pembahasan}

Dalam era industri 4.0 menuntut setiap individu agar dapat berjalan beriringan dengan teknologi yang telah berkembang sangat cepat. Hampir setiap pekerjaan dapat dibantu atau akan lebih mudah dikerjakan dan berhasil lebih baik bila dikerjakan dengan memanfaatkan perkembangan teknologi. Sehingga pemanfaatan teknologi dalam melakukan pekerjaan dapat meningkatkan produktivitas dan kinerja.

Produktivitas dan kinerja yang meningkat ini secara otomatis dapat mempertahankan daya saing dengan perusahaan sejenis. Sekolah xxx saat ini mengalami masalah mempertahankan daya saing. Hal ini dapat dilihat dari kecenderungan jumlah murid yang terus menurun dalam tiga (3) tahun ajaran terakhir terutama pada divisi SMP, SMK dan SMK.

Keluaran (output) dari guru adalah tersampaikannya materi dengan baik kepada peserta didik sehingga peserta didik menjadi puas. Jumlah peserta didik yang terus menurun tersebut dapat menjadi cermin bagi manajemen bahwa peserta didik tingkat SMP, SMK dan SMA tidak puas belajar di sekolah xxx. Manajemen sekolah sudah menyediakan berbagai perangkat pendukung agar guru dapat lebih mudah dalam menyampaiakan materi pelajaran, seperti tersedianya proyektor di setiap ruang kelas dan dua (2) laboratorium komputer selain komputer yang tersedia di setiap ruang guru. Manajemen juga menyelenggarakan pelatihan agar guru dapat memanfaatkan fasilitas tersebut dalam bekerja. Hal ini dilakukan karena pihak manajemen menyadari betul bahwa peserta didik pada era sekarang ini sudah sangat akrab dengan teknologi, sehingga dalam penyampaian materi pelajaran sebisa mungkin harus memanfatkan teknologi agar lebih akrab dan dapat diterima oleh peserta didik dan bukan lagi menyampaiakan materi seratus persen secara konvensional. Sehingga dengan memanfaatkan fasilitas yang sudah disediakan diharapkan guru dapat meningkatkan produktivitas dan kinerjanya.

Hasil penelitian ini menunjukan produktivitas dan kinerja guru masih rendah, belum mencapai angka 90\%. Presentase besarnya produktivitas kerja dapat dijelaskan oleh penguasaan teknologi dan disiplin kerja sebesar 65,3\% dan kinerja karyawan dapat dijelaskan oleh penguasaan teknologi, disiplin kerja dan produktivitas kerja sebesar $82,1 \%$. Kinerja guru dapat ditingkatkan melalui produktivitas. Manajemen harus memperhatikan penguasaan teknologi karena mempunyai kontribusi yang lebih besar terhadap produktivitas, namun demikian manajemen tidak boleh mengabaikan disiplin kerja para guru.

\section{Kesimpulan}

Kinerja karyawan adalah nilai serangkaian perilaku pekerja yang memberikan kontribusi, baik secara positif maupun negatif untuk mencapai tujuan organisasi Colquitt et al, 2015. Pengusaan teknologi, disiplin dan produktivitas memberikan kontribusi terhadap kinerja guru di sekolah xxx. Hasil ini menjelaskan bahwa guru yang dapat mengusai dan menggunakan peralatan kerja berbasis teknologi dengan baik maka akan memiliki produktivitas yang juga baik. Seperti yang dijelaskan oleh Oliver dan 
Towers tahun 2000, bahwa penguasaan teknologi merupakan seperangkat ketrampilan dan pemahaman yang dibutuhkan oleh individu sehingga memungkinkan penggunaan teknologi informasi yang sesuai dengan kebutuhan mereka. Guru agar dapat lebih mudah dalam menyampaikan materi pelajaran kepada peserta didik memerlukan ketrampilan dan pemahaman tentang teknologi informasi.

Mathis tahun 2011 memberi penjelasan mengenai disiplin, yaitu suatu bentuk pelatihan yang menegakkan aturan organisasi. Guru yang bermasalah seringkali memengaruhi sistem disiplin. Guru yang tingkat disiplinnya rendah cenderung menunjukkan produktivitas dan kinerja yang rendah pula. Guru yang tingkat disiplinnya rendah, dalam melaksanakan pekerjaan kurang mematuhi aturan yang telah ditentukan oleh manajemen. 


\section{BIBLIOGRAFI}

Bahri, Samsul. (2016). Pengaruh pengembangan karier dan kompetensi terhadap produktivitas kerja serta implikasinya pada kinerja pegawai dinas pu bina marga wilayah kerja Sumatera Selatan. Jurnal Ecoment Global: Kajian Bisnis Dan Manajemen, 1(1), 21-50.Google Scholar

Colquitt, J. A., Jweffery A. L, and Michael J. W. (2011). Organizational Behavior, McGraw-Hill, New York.

Ferreira, A., \& Du Plessis, T. (2009). Effect of online social networking on employee productivity. South African Journal of Information Management, 11(1), 1-11. Google Scholar

Jeffrey, Ignatius, \& Soleman, Mahmud. (2017). The effect of work discipline, achievement motivation and career path toward employee performance of The National Resilience Institute of The Republic of Indonesia. International Journal of Application or Innovation in Engineering \& Management (IJAIEM), 6(8). Google Scholar

Karim, Farashintha Julhija. (2016). Pengaruh Penguasaan Teknologi Informasi, Pendidikan Dan Disiplin Kerja Terhadap Produktivitas Pegawai Bps Provinsi Jawa Timur. E-Journal Manajemen" Branchmarck", 2(4). Google Scholar

Kholidia Masitah, Fariani. (2017). Strategi Pencitraan dan Komunikasi dalam Upaya Meningkatkan Jumlah Siswa (Studi Kasus di SMP Muhammadiyah 1 Surabaya). Inspirasi Manajemen Pendidikan, 5(1). Google Scholar

Mathis, R. L. \&. Jackson. J. H. (2011). Manajemen Sumber Daya Manusia, edisi 9. Jakarta: Penerbit Salemba Empat.

Mutuku, Mirriam N., \& Nyaribo, Wycliffe Misuko. (2015). Effect of Information Technology on Employee Productivity in Selected Banks in Kenya. Review of Contemporary Business Research, 4(1), 49-57. Google Scholar

Muzakki, M. H., Susilo, H., \& Yuniarto, S. R. (2016). Pengaruh penggunaan teknologi informasi terhadap kinerja karyawan (studi pada karyawan PT. Telkom Pusat Divisi Regional V Surabaya). Jurnal Administrasi Bisnis, 39(2), 169-175.

Noel, Flavia Reva, Lapian, SLHV Joyce, \& Pandowo, Merinda. (2017). The affect of work discipline and competence on employee performance (Case Study At Balai Kesehatan Mata Masyarakat Sulawesi Utara). Jurnal EMBA: Jurnal Riset Ekonomi, Manajemen, Bisnis Dan Akuntansi, 5(3). Google Scholar

Nuskiya, Aliyar Fathima. (2018). The Effect of Information Technology on Employees' Performance in the Banking Industry in Sri Lanka. Empirical Study Based on the Banks in Ampara District. European Journal of Business and Management. ISSN, 1905-2222. Google Scholar 
Oguche, D. (2017). Impact of Information and Communication Technology (ICT) Literacy competence on Job Performance of Librarians in Federal University Libraries in Nigeria. The Information Technologist, 13(1). Google Scholar

Oliver, Ron, \& Towers, Stephen. (2000). Benchmarking ICT literacy in tertiary learning settings. Learning to Choose: Choosing to Learn. Proceedings of the 17th Annual ASCILITE Conference, 381-390. Google Scholar

Saha, A., \& Majumder, S. (2017). Impact of information technology on performance appraisal. International Research Journal of Human Resources and Social Sciences (IRJHRSS). 81-89.

Saleh, Abdul Rachman, \& Utomo, Hardi. (2018). Pengaruh Disiplin Kerja, Motivasi Kerja, Etos Kerja dan Lingkungan Kerja Terhadap Produktivitas Kerja Karyawan Bagian Produksi di PT. Inko Java Semarang. Among Makarti, 11(1). Google Scholar

Sridaryono, Aguk. (2019). Pengaruh Kompetensi dan Kompensasi Terhadap Kinerja Pegawai Negeri Sipil Melalui Produktivitas Kerja Sebagai Variabel Intervening di Politeknik Angkatan Darat Malang. SKETSA BISNIS, 6(2), 99-111. Google Scholar

Sutrisno, Sugeng. (2013). Pengaruh disiplin kerja dan motivasi kerja terhadap kinerja pegawai negeri sipil (studi di kantor dinas sosial provinsi jawa tengah). Jurnal Ilmiah Dinamika Ekonomi Dan Bisnis, 1(1), 25040. Google Scholar

Suyono, Wahyu Galih Pramudito. (2014). Pengaruh Motivasi, Kemampuan dan Disiplin terhadap Kinerja Karyawan. Fakultas Ekonomi Dan Bisnis Universitas Dian Nuswantoro, 1-9. Google Scholar

Wardoyo, Dewi Tri Wijayati. (2016). The Influence of the Discipline and Compensation against Work Productivity (Study on the Security Services Company, PT Garuda Milky Artha Surabaya). International Journal of Business and Management, 11(1), 64. Google Scholar

Wexley, Kenneth N., \& Yukl, G. A. (1977). Organizational Behavior and Personal Psychology, Richard D. Irwin Inc., Homewood, Illinois. Google Scholar

Williams, Brian K., Sawyer, Stacey C., \& Hutchinson, Sarah E. (1999). Using information technology: A practical introduction to computers \& communications. ERIC. Google Scholar

Yuvaraj, S., \& Nadheya, R. (2018). A study on the role of technology on employee behaviour and their performance. Int. J. Mech. Eng. Technol, 9(7), 244-251. Google Scholar 
Yani, Amri Darwis, Yulina Eva Riany

Zainal, Henni. (2017). Influence of Work Motivation and Discipline on Work Productivity. 2nd International Conference on Education, Science, and Technology (ICEST 2017). Atlantis Press.

\section{Copyright holder :}

Yani, Amri Darwis dan Yulina Eva Riany (2021)

\section{First publication right :}

Jurnal Syntax Idea

This article is licensed under:

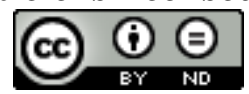

